\title{
FATORES RELEVANTES PARA A IMPUNIDADE DE AGENTES ESTATAIS NA AMÉRICA LATINA: um estudo empírico sobre o descumprimento de sentenças da Corte Interamericana
}

Rodrigo Leite

\section{Palavras-Chave}

corte interamericana / impunidade / cumprimento / agentes estatais

\section{SUMÁRIO}

\section{Introdução}

20 Sistema Interamericano de Direitos Humanos

3 Razões para se investigar empiricamente a impunidade a partir do descumprimento das sentenças da Corte Interamericana

40 conceito de impunidade 5 Fatores que podem ter relação com a não persecução penal dos agentes responsáveis

\section{Metodologia}

7 Análise dos resultados

8 Análise dos resultados

9 Referências
1 Graduado em Direito pela Universidade Católica de Pernambuco. Mestre em Direito pela Universidade de Lisboa. Doutor em Ciência Política pela UFPE. Professor Adjunto do Curso de Direito da Universidade Federal Rural do Semi-Árido (UFERSA) e Coordenador da Pós Graduação em Direito Constitucional e Tributário na mesma Instituição.

\section{Resumo}

O presente artigo busca identificar quais são os fatores incidentes nos processos criminais dos Estados condenados pela Corte Interamericana, que são relevantes para se analisar a impunidade dos agentes estatais responsáveis por violações de direitos humanos. Como metodologia, o trabalho utiliza a amostra de dados do estudo de Zaverucha e Leite (2016), que revelou que nas sentenças proferidas pela Corte entre 2001 e 2013, a medida de reparação para os Estados investigar, julgar e sancionar os agentes estatais culpados de crimes nunca foi totalmente cumprida pelos países. Desta forma, através de uma pesquisa qualitativa, do tipo exploratória-descritiva, utilizando-se do método indutivo, e a partir das informações contidas nas resoluções de supervisão de cumprimento de sentenças da Corte, identificaram-se os fatores que podem explicar o descumprimento desta medida de reparação. A análise dos dados mostrou que o fator tempo tem importância, pois quanto mais recente o crime, maior a tendência para o sucesso na realização da persecução criminal. A quantidade de réus também foi caracterizada como um elemento importante, sendo mostrado que mais da metade dos casos analisados não tinham réus individualizados ou as investigações das violações não foram concluídas, e quando individualizados, quanto maior a quantidade de réus, maior a dificuldade. A análise também mostrou que a maioria dos casos estão na fase investigatória, e não no Poder Judiciário. Por fim, o tipo de crime foi considerado como fator relevante, sendo verificado que quando existe o crime de desaparecimento forçado, a tendência é que o processo criminal não seja cumprido. 


\section{RELEVANT FACTORS FOR THE IMPUNITY OF STATE AGENTS IN LATIN AMERICA: an empirica study about noncompliance of judgments of the inter-american court}

Rodrigo Leite

\section{KEYWORDS}

Inter-American Court / Impunity / Compliance / State Agents.

\section{Resumo}

This article seeks to identify which factors are involved in the criminal prosecutions of states condemned by the Inter - American Court, which are relevant to analyze the impunity of state agents responsible for human rights violations. As a methodology, the study uses the data sample from the study of Zaverucha and Leite (2016), which revealed that in the judgments handed down by the Court between 2001 and 2013, the reparation measure for the states to investigate, prosecute and punish state agents guilty of crimes has never been fully met by countries. Thus, through a qualitative research, of the exploratorydescriptive type, using the inductive method, and from the information contained in the resolutions of supervision of compliance with the Court's judgments, we identified the factors that may explain the noncompliance of this measure of reparation. The analysis of the data showed that the time factor is important, since the more recent the crime, the greater the tendency to succeed in carrying out the criminal prosecution. The number of defendants was also characterized as an important element, showing that more than half of the cases analyzed did not have individual defendants or investigations of violations were not completed, and when individualized, the greater the number of defendants, the greater the difficulty. The analysis also showed that most of the cases are in the investigative phase, and not in the Judiciary. Finally, the type of crime was considered as a relevant factor, and it was verified that when there is a crime of forced disappearance, the tendency is that the criminal process is not fulfilled. 


\section{Introdução}

A Corte Interamericana de Direitos Humanos (adiante Corte Interamericana ou Corte) é um Tribunal internacional que julga violações de direitos humanos dos Estados que se submeteram à sua jurisdição e que fazem parte do Sistema Interamericano de Direitos Humanos. Ainda estabelecido em uma estrutura clássica, muito respeitadora da soberania dos países, julga os casos que Ihe são submetidos e profere decisões judiciais responsabilizando internacionalmente os Estados. O objetivo destas condenações é fazer com que os países reparem as violações sofridas pelas vítimas, seja, por exemplo, através do pagamento de indenizações ou da investigação e julgamento dos culpados. A análise deste último tipo de medida de reparação é o foco deste trabalho.

Neste contexto, o trabalho publicado por Zaverucha e Leite (2016) identificou um alto índice de descumprimento nas sentenças da Corte Interamericana e, em específico, a ordem para que os países investiguem, julguem e sancionem os agentes estatais suspeitos de violações de direitos humanos. Em verdade, dentro dos critérios de seleção de casos estabelecido pelos autores, nenhuma sentença teve esta medida totalmente cumprida, ou seja, há uma verdadeira impunidade dos agentes estatais em seus países. Os resultados deste trabalho coincidem com pesquisas empíricas anteriores sobre o cumprimento de sentenças da Corte Interamericana, como os de Cavallaro e Brewer (2008), Bash et al (2010), Hawkins e Jacoby (2010), Huneeus (2011) e González-Salzberg (2010), que demonstraram que os Estados condenados pela Corte Interamericana costumam cumprir as medidas de reparação mais fáceis, como as que envolvem apenas o poder executivo, enquanto que as repara- ções que necessitam da ação de órgãos de poderes distintos possuem o cumprimento mais lento.

O conceito de impunidade aqui adotado aborda justamente o fato de que, após a condenação do Estado pela Corte Interamericana, os países deveriam realizar todos os esforços para investigar e julgar os crimes cometidos por agentes estatais. No entanto, os órgãos nacionais não levam os casos adiante.

Neste sentido, o objetivo da proposta deste artigo é pesquisar que fatores têm feito com que os agentes estatais suspeitos de violações de direitos humanos julgadas pela Corte Interamericana não sejam julgados e condenados em seus países. A hipótese inicial é a de que os processos criminais acabam sendo sobrestados na fase de investigação e que o tempo entre a data do fato e a sentença da Corte é muito grande, o que faz com que a volta à investigação ordenada pela Corte seja prejudicada ante a dificuldade de obtenção de provas.

Como metodologia, será realizada uma pesquisa qualitativa, do tipo exploratóriadescritiva, de forma a identificar fatores (categorias) que possam explicar o descumprimento desta medida de reparação. Buscar-se-á identificar se os processos estão encontrando obstáculos na fase de investigação ou se é o Poder Judiciário que está criando entraves para o andamento processual. Além desta questão, o tipo de crime envolvido e o número de réus serão classificados e o fator tempo também será observado, no intuito de identificar se a distância temporal entre a data do crime e a da sentença condenatória da Corte Interamericana pode ter alguma correlação com o (des) cumprimento. Assim, o estudo ten- 
tará encontrar elementos chaves inerentes ao próprio processo criminal nos países condenados, realizando um processo criativo a partir de um mecanismo indutivo.

Cabe ressaltar que na literatura da área jurídica ainda não há um estudo com este grau de aprofundamento, que complementaria a pesquisa elaborada por Zaverucha e Leite (2016). A presente pesquisa demandou a análise criteriosa de sessenta e duas sentenças da Corte Interamericana que ordenou a condenação de agentes estatais suspeitos de violações de direitos humanos, além das resoluções de supervisão de cumprimento para cada sentença, que variam em quantidade para cada caso. Estas resoluções de supervisão da Corte Interamericana é que nos fornecerão os dados necessários para a coleta de dados, podendo ser encontradas no website do Tribunal.

Neste sentido, o artigo foi estruturado da seguinte forma: inicialmente será apresentado como funciona o Sistema Interamericano de Direitos Humanos e a Corte e, em seguida, serão apresentados os motivos para se investigar empiricamente a impunidade proveniente do descumprimento de sentenças da Corte Interamericana. Logo após será estabelecida a metodologia e, por fim, a análise dos resultados.

\section{O sistema interamericano de direitos humanos}

A Corte Interamericana de Direitos Humanos e a Comissão Interamericana são os dois principais órgãos internacionais destinados, no continente americano, à proteção dos direitos humanos e fazem parte do denominado Sistema Interamericano de Direitos Humanos. São principais porque atuam diretamente nas demandas do Sistema. No entanto, existem também órgãos políticos da Organização dos Estados Americanos (OEA) que participam no processo de respeito às obrigações oriundas dos tratados, a exemplo da Assembleia Geral da OEA, mas que atuam subsidiariamente.

A Comissão Interamericana foi estabelecida em 1959 e iniciou suas funções em 1960. Por sua vez, a OEA adotou a Convenção Americana de Direitos Humanos (adiante Convenção Americana ou CADH) em 1969 e a partir de seu mandamento criou a Corte Interamericana de Direitos Humanos, que começou a atuar em 1979. Cabe ressaltar que no momento da criação da Corte, cada país deveria aderir à jurisdição do Tribunal, ou seja, ter a possibilidade de indicar juízes e serem julgados pelo órgão.' Neste momento, os Estados Unidos e o Canadá não ratificaram a adesão à Corte e, assim, não podem ser julgados por violações à CADH. No entanto, qualquer país que não aceitou a jurisdição do Tribunal pode solicitar a adesão a qualquer tempo. ${ }^{2}$

Neste Sistema, a Corte Interamericana e a Comissão funcionam em complementaridade, mas com papéis distintos. A Comissão atua no primeiro passo do Sistema, que consiste na análise da admissibilidade das denúncias de violações de direitos humanos $^{3}$, tentando encontrar soluções consensuais entre as partes bem como tem poderes investigatórios e a faculdade de apresentar relatórios sobre as condições dos direitos humanos nos países.

\footnotetext{
1 Assim determina o art. 62.1 da CADH: "Todo Estado-parte pode, no momento do depósito do seu instrumento de ratificação desta Convenção ou de adesão a ela, ou em qualquer momento posterior, declarar que reconhece como obrigatória, de pleno direito e sem convenção especial, a competência da Corte em todos os casos relativos à interpretação ou aplicação desta Convenção".

2 Uma lista com os países que fazem parte da CADH encontra-se em: http://www.oas.org/dil/esp/tratados_B-32_Convencion_Americana_sobre_Derechos_Humanos.htm

3 Neste trabalho, quando se fizer referência a "violações de direitos humanos", entenda-se que são violações à CADH e os demais tratados que fazem parte do Sistema Interamericano.
} 
Por sua vez, a Corte é responsável por demandas contenciosas (judiciais), por emitir medidas provisórias e por proferir opiniões consultivas. É o órgão judicial do sistema e atua após a Comissão decidir levar o caso até o Tribunal. A função do Tribunal é julgar as violações aos tratados que compõem o Sistema e responsabilizar os Estados. Assim, frise-se que a Corte não é uma instância recursal ou tem poderes para revogar ou cassar decisões judiciais nacionais. O seu objetivo é apenas analisar as violações aos tratados do sistema e responsabilizar o país por tal fato, independente do agente ou poder (executivo, legislativo ou judiciário) nacional que tenha cometido a violação.

Desta forma, é importante esclarecer que o Sistema Interamericano de Direitos Humanos é composto de uma complexa estrutura de mecanismos e procedimentos previstos tanto pela Carta da OEA como pelos dispositivos estabelecidos na $\mathrm{CADH}$ e seus protocolos adicionais. Assim, o seu funcionamento tem como base os tratados referidos, sendo que para fundamentar uma sentença, a Corte pode se utilizar de outros tratados que fazem parte do Sistema, como por exemplo, a Convenção Interamericana para Prevenir e Punir a Tortura, o Protocolo de San Salvador, que é um protocolo adicional à CADH em matéria de direitos econômicos, sociais e culturais, e a Convenção de Belém do Pará, que visa a prevenção, punição e erradicação da violência contra a mulher. ${ }^{4}$

Pode-se afirmar também que, como aconteceu na Europa, o Sistema Interamericano de Direitos Humanos foi precedido por um organismo internacional de característica regional - que é a Organização dos Estados Americanos. Ou seja, tanto a Comissão In- teramericana quanto a Corte são órgãos da OEA. A principal diferença é que o Sistema Europeu surgiu como uma resposta a atrocidades da Segunda Guerra Mundial e o Sistema Interamericano nasce a partir da interação política entre os países (García, 2007, p. 11; Carulla, 2007, pp. 17-18) e o aumento de queixas por violações de direitos humanos na década de 60 e 70 do século passado.

Em relação à Corte Interamericana, cabe ressaltar que nos casos da competência contenciosa (judicial), a Corte Interamericana emite uma sentença com valor jurídico vinculante para as partes, na qual determina ou não a violação da CADH e dos demais tratados que fazem parte do Sistema Interamericano. Os artigos 67 e 68.1 da CADH determinam que a sentença da Corte será definitiva e inapelável e que os Estados se comprometem a cumprir a decisão da Corte em todo caso em que forem partes.

O conteúdo destas sentenças pode ser bastante amplo, pois o conceito de reparação da CADH determina que, além de se garantir à vítima o gozo do seu direito ou liberdade violados, se for procedente, que se reparem as consequências da medida ou situação que gerou a vulneração destes direitos e se pague uma indenização justa. A Corte Interamericana tem diversificado o seu leque de medidas de reparação, determinando aos países condenados, por exemplo, que façam obras em homenagens às vítimas, que sejam criados cursos de preparação de corpos policiais, bolsas de estudo, oferecimento de tratamento de saúde e psiquiátrico, que se investigue e sancione os culpados de violações, entre outros.

Contudo, a realidade é que em alguns países que fazem parte do sistema, existem barreiras para a execução completa destas 
sentenças. Em algumas situações, o Poder Executivo até possui vontade de implementar as medidas de reparação ordenadas pela Corte Interamericana, mas as próprias normativas internas impedem os atores públicos de fazer cumprir as ordens, ainda mais quando as medidas devem ser implementadas por outro poder. Aliado a estes fatos, existe a própria burocracia dos órgãos públicos, aliado a outros fatores, que impedem uma execução rápida das sentenças.

No âmbito do Sistema Interamericano, para controlar e supervisionar o cumprimento destas sentenças, foi criado um mecanismo de supervisão de caráter duplo: a própria Corte realiza um procedimento de supervisão (etapa judicial) e existe também a possibilidade de supervisão em nível político, de caráter subsidiário, com a atuação do Conselho Permanente (e sua Comissão de Assuntos Jurídicos e Políticos) e da Assembleia Geral da OEA.

$\mathrm{Na}$ etapa judicial, ao proferir a sentença com as medidas de reparações, a Corte Interamericana geralmente se reserva à faculdade de supervisionar o cumprimento de suas próprias decisões. O trabalho de supervisão do Tribunal é o primeiro passo neste processo de controle, e requer um estudo cuidadoso, consistindo em determinar se o Estado condenado cumpriu com suas obrigações na forma e no tempo previsto na sentença respectiva. Além disso, a Corte costuma realizar audiências com as partes envolvidas no caso (o Estado, a Comissão Interamericana e os representantes das vítimas, assim como recebe relatórios de cada um sobre o estado de cumprimento), para que se possa discutir o avanço no respeito às medidas de reparação ordenadas.

Posteriormente, o Tribunal emite uma resolução de supervisão, onde resume as in- formações sobre as medidas que já foram cumpridas pelo Estado condenado, as que foram parcialmente cumpridas e as que não tiveram nenhum tipo de ato volitivo do Estado para sua implementação, além de estipular um prazo para que o Estado, a Comissão e as vítimas apresentem novo relatório sobre o cumprimento das medidas ordenadas na sentença.

A Corte Interamericana deve também incluir os casos que não foram totalmente cumpridos em seu Relatório Anual e apresentá-los ante a Comissão de Assuntos Jurídicos e Políticos (CAJP) do Conselho Permanente, no próprio Conselho, e nas Reuniões Ordinárias da Assembleia Geral da OEA. Estes, a princípio, seriam os órgãos políticos responsáveis pela supervisão do cumprimento das sentenças da Corte Interamericana. Contudo, grande parte da doutrina afirma que a atitude destes órgãos frente à discussão dos temas que são objetos de atenção da Corte Interamericana em seus relatórios anuais é apática e desinteressada (Briceño-Donn, 2001, p. 6; Krsticevic, 2007, p. 35; Pasqualucci, 2003, p. 343-346; Schneider, 2012, p. 201-202).

Assim, importância fundamental para este trabalho será dada sobre a etapa judicial de supervisão de cumprimento das sentenças. É através das resoluções de supervisão emitidas pela Corte Interamericana que se tem um diagnóstico do cumprimento de cada medida de reparação ordenada nas sentenças da Corte Interamericana.

\section{Razões para se investigar empiricamente a impunidade a partir do descumprimento das sentenças da Corte Interamericana}

Dentro do rol de sentenças da Corte Interamericana existe uma grande quantidade 
de casos nos quais os países foram condenados em razão do cometimento, por parte de suas forças policiais ou militares, ou de outros agentes do Estado, de crimes como assassinato, desaparecimento forçado, estupro, tortura, lesões corporais, massacre de determinados grupos étnicos, entre outras violações de direitos humanos. Neste trabaIho, serão pesquisados estes tipos de crimes.

Grande parte destes delitos são legados de períodos ditatoriais, no sentido de que essas práticas autoritárias foram implantadas durante e após tais regimes, e que se tornaram instituições informais com o manto da impunidade. Refletem ainda casos que também foram cometidos em períodos de ditadura militar. São massacres de populações indígenas, mortes e torturas em presídios, assassinatos e prisões de opositores políticos, espancamentos por policiais. Estes são apenas alguns exemplos de casos julgados pelo Tribunal Interamericano.

Ressalta-se que, aqui, as "violações de direitos humanos" se referem a violações de direitos garantidos na Convenção Americana de Direitos Humanos (CADH), que contém um rol de direitos humanos a serem protegidos, além de abranger outros tratados que fazem parte do Sistema.

Desta forma, o foco deste trabalho são casos nos quais agentes estatais, ou de particulares à serviço do Estado, agiram de forma a cometer crimes, cujos casos foram julgados pela Corte Interamericana. Nestas condenações que os países sofreram, entre as medidas de reparação estabelecidas nas sentenças, está a que determina a investigação, o julgamento e a sanção dos culpados. No entanto, nos casos que serão objetos de análise, nenhuma sentença da Corte Interamericana que teve este tipo de ordem foi totalmente cumprida, e, em consequência, muitos agentes estatais continuam impunes em seus Estados. Esta é a impunidade que será detalhada, de forma a identificar que fatores estão incidindo para que ela ocorra.

Desde já, observe-se que, em grande parte dos casos, há um lapso temporal considerável entre a violação de direitos humanos (fato gerador do caso) e a sentença da Corte Interamericana, o que dificulta a obtenção de novas provas para que se condenem os culpados em seus países. Um bom exemplo é o caso Radilla Pacheco contra o México, no qual o Tribunal ressaltou em 2013 que já faziam mais de 39 anos do desaparecimento das vítimas sem que se tenha terminado a investigação policial dos fatos, que seria a primeira etapa de um procedimento de julgamento. Deste modo, a Corte tem reconhecido que o tempo guarda uma relação diretamente proporcional com a limitação, e, em alguns casos, a impossibilidade - para se obter provas e testemunhos, dificultando ou tornando ineficaz a prática de diligências para o esclarecimento dos fatos, identificar os autores e determinar as responsabilidades penais. Mesmo assim, nada exime dos Estados executarem a sentença em seus ordenamentos jurídicos. ${ }^{5}$

Por sua vez, Beristan (2009, pp. 349-351) sustenta que a falta de investigação, julgamento e sanção dos culpados de violações de direitos humanos ordenado pela Corte Interamericana é resultado da contribuição das falências estruturais dos sistemas de justiça nacionais e, assim, o longo tempo e características da investigação de um caso complexo acumulam problemas durante anos, auxiliada pela inércia dos sistemas judiciais

5 Corte Interamericana. Caso Radilla Pacheco vs. México. Resolução de Supervisão de Cumprimento de Sentença, de 14 de maio de 2013, pár. 12. 
nacionais. Assim, sustenta que estas dificuldades são um problema estrutural de difícil solução à curto prazo para os países do Sistema Interamericano.

Neste sentido, Beristain (2009, p. 352) explica que a falta de cumprimento da justiça nacional depois que as sentenças são proferidas pela Corte Interamericana é vista por muitos interlocutores que trabalham com o Sistema Interamericano como uma falta de poder da Corte, cuja autoridade não está respaldada pela capacidade executiva da própria OEA.

Em outro âmbito, os estudos empíricos sobre o cumprimento de sentenças da Corte Interamericana de Cavallaro e Brewer (2008), Bash et al (2010), Hawkins e Jacoby (2010), Huneeus (2011) e González-Salzberg (2010), coincidiram em mostrar que os Estados condenados costumam cumprir as medidas de reparações mais fáceis, como indenizações, medidas simbólicas, e medidas envolvendo apenas a ação do Poder Executivo, que em geral são cumpridas com mais frequência e mais rapidamente, enquanto que medidas que demandam a ação de dois ou mais poderes, costumam ser cumpridas parcialmente. Este é um tipo de comportamento que Hillebrecht (2014, p. 42-43) denominou de "cumprimento à la carte".

Outros trabalhos empíricos procuraram dar ênfase nas questões internas dos Estados como responsáveis pelo cumprimento (ou não) das sentenças do Tribunal Europeu dos Direitos Humanos e da Corte Interamericana. Anagnostou e Mungiu-Pippidi (2014) ressaltaram que a capacidade da infraestrutura jurídica e a eficácia do governo de um estado possui relação direta com o sucesso e a rapidez da execução de sentenças do Tribunal Europeu dos Direitos Humanos.
Huneeus (2011), pesquisando o cumprimento de sentenças da Corte Interamericana, sustenta que quando as medidas de reparação envolvem poderes distintos, os interesses, ideologias e configurações institucionais diferem do Poder Executivo e, assim, quando a medida de reparação envolve dois poderes como o Poder Executivo e o Legislativo, ou Executivo e Ministério Público, a dificuldade em cumprir tem relação com a natureza do ator e não com a ação. No entanto, quando se trata das medidas para se investigar, julgar e sancionar, que envolve as polícias, Ministério Público e Poder Judiciário, a dificuldade tem mais relação (ainda quem nem sempre) com questões práticas em cumprir esta tarefa, pois muitas vezes os agentes estatais responsáveis são protegidos, garantindo-se a impunidade, ainda que isto não seja uma constante nos estados latino-americanos, havendo variação nos motivos do não cumprimento.

As características dos julgamentos e, principalmente, dos tipos de medida de reparação também foram reconhecidos como fatores determinantes para o cumprimento das sentenças. Medidas que envolvem dois poderes ou mais para execução, como as reparações para se criar ou modificar leis, encontrar pessoas desaparecidas, e a ordem para se investigar, julgar e sancionar os culpados de violações, quase sempre trazem dificuldades de implementação.

Grewal e Voeten (2012) e Voeten (2014), estudando o cumprimento de sentenças do Tribunal Europeu dos Direitos Humanos, defendem que a capacidade da burocracia e do Poder Judiciário do país e a pressão no Poder Executivo (constrangimentos) exercem influência no cumprimento das medidas de reparação. No entanto, as características das medidas de reparação e o tipo de 
direito violado, em conjunto com o tempo de execução de cada medida de reparação, são relevantes quando se analisa o cumprimento ou não das sentenças. Estes fatores devem ser trabalhados conjuntamente, na visão dos autores, para se ter um panorama mais fidedigno das causas de (des) cumprimento. Poertner (2013) também confirmou que a capacidade burocrática nacional e a força do poder judiciário possuem efeito positivo no cumprimento das sentenças, havendo variação da influência a depender do tipo de medida de reparação.

Desta forma, este trabalho irá se centrar nas características dos julgamentos emitidos pela Corte Interamericana, em específico, das medidas de reparação que ordenam a investigação e julgamento dos que cometem violações de direito humanos. Assim, além da questão temporal, buscar-se-á identificar quais fatores são relevantes para se analisar a impunidade dos agentes estatais perante o sistema judicial de seus países.

\section{0 conceito de impunidade}

O vocábulo impunidade corresponde nominalmente à falta de castigo (Álvarez, 2012, p. 3; Carvalho Filho, 2004, p. 181; Le Clercq; Cháidez; Rodríguez, 2016, p. 71), que é uma acepção mais aproximada do direito penal.

No entanto, Le Clercq, Cháidez e Rodríguez (2016, p. 4) apontam que apesar da ideia de impunidade remeter a uma relação simples entre um ato delitivo e a existência de uma sanção, o fenômeno é multidimensional e pluricausal, podendo ter correlação com outros problemas, como corrupção, violência, insegurança, acesso desigual à justiça ou violações dos direitos humanos.

Ambos (1999, p. 37-42) detalha ainda mais o fenômeno da impunidade e explica a existência da impunidade processual, que tem relação com as etapas processuais de um procedimento criminal. Esse tipo de impunidade estaria subdividida em: (a) a impunidade de fato, ante a ausência de denúncia dos fatos puníveis; (b) impunidade investigativa, por uma deficiente atividade de investigação; (c) impunidade por congestão, devido à sobrecarga da justiça penal; (d) impunidade legal, ante a presença de leis que causam impunidade; e (e) impunidade delituosa, forma mais fática da impunidade, que se caracteriza por medidas coativas contra as partes no processo.

Para a Corte IDH, o conceito de impunidade está relacionado diretamente com a obrigação dos Estados em reparar violações de direitos humanos e, em especial, a obrigação de investigar, processar e sancionar os responsáveis (Matute, 2010, p. 264). Nesse sentido, a Corte IDH parece utilizar mais o conceito de impunidade processual quando aborda esse tema. Essa medida tem conotação semelhante aos Princípios da Luta contra Impunidade, elaborado pela Organização das Nações Unidas (ONU), por meio do Relatório de Diane Orentlicher, em que o Princípio 31 estabelece que "toda violação de um direito humano dá lugar a um direito da vítima a obter uma reparação, o qual implica o dever do Estado de reparar e o direito de dirigir-se contra o autor" (Orentlicher, 2004, p. 17, tradução nossa).

Para este trabalho, o conceito de impunidade escolhido terá relação com o descumprimento das sentenças da Corte IDH, mais especificadamente a execução nos países da ordem proferida pelas decisões da Corte IDH que determinam aos Estados condenados que se investiguem, julguem e sancionem os culpados de violações. Esse traço da 
impunidade se assemelha mais ao aspecto penal (ausência de punição), em específico, a impunidade processual (Ambos, 1999), pois o objetivo é identificar que elementos nos processos criminais nacionais estão fazendo com que os autores de crimes não sejam julgados.

Deve-se ressaltar que a Corte IDH não é um Tribunal com poder de emanar ordem de execução imediata aos órgãos estatais. O Tribunal condena o país pela violação de um direito humano e solicita que o Estado investigue, julgue e sancione os responsáveis. O papel dos juízes é determinar se uma prática estatal é legal ou ilegal e especificar uma medida de reparação (Alter, 2014). Não é a Corte IDH que fará a gestão do processo penal nos Estados, ela apenas recebe a informação se o Estado cumpriu ou não essa ordem. Caso não tenha cumprido totalmente, a sentença continua em supervisão por tempo indeterminado, e quando não se cumpre os responsáveis continuam impunes.

Os países possuem suas normas e procedimentos, mas por alguma razão não há consequências concretas para punir os responsáveis. Essa é a impunidade fática descrita por Álvarez (2012, p. 4). E entender os elementos que estão por trás do retardamento dos processos tendentes a cumprir a ordem da Corte IDH nos países é que será o objetivo deste trabalho.

Este estudo é importante porque a reputação da Corte IDH é influenciada especialmente pelo cumprimento de suas sentenças (Silva e Echeverria, 2015, p. 398; Dothan, 2011, p. 116).

\section{Fatores que podem ter relação com a não persecução penal dos agentes res- ponsáveis}

Dentro desse processo de conhecimento sobre o tema da impunidade dos agentes estatais, Beristain (2008) elaborou uma importante obra sobre reparações a partir de casos julgados pela Corte IDH, por meio de análise de casos reais e entrevistas com vítimas, advogados que trabalham com o SIPDH e membros de organizações internacionais e não governamentais. O autor aponta que se existe algo que põe à prova a vontade de cumprimento dos Estados para com as decisões da Corte IDH, é a investigação, julgamento e sanção dos culpados.

Um estudo efetuado pela Oficina en Washington para Asuntos Latinoamericanos (WOLA) revelou que o nível de impunidade em casos de abusos de militares contra civis no México é altíssimo. O relatório apontou que durante quatro anos, entre 2012 e 2016, O Ministério Público Federal desse país (Procuraduría General de la República) apresentou um total de 505 inquéritos de investigação contra elementos das forças armadas; no entanto, somente 16 sentenças condenatórias foram proferidas na justiça civil, o que resulta em apenas 3,2\% de condenações (Suárez-Enríquez, 2017). Entre os crimes cometidos, estavam (em ordem decrescente): tortura, abuso de autoridade, desaparecimento forçado, violência sexual e homicídio.

Entre os elementos encontrados no México que favorecem a impunidade, o relatório destaca o largo tempo dos processos no Poder Judiciário, a falta de provas coletadas pelo Ministério Público Federal, alteração de locais do crime e testemunhos falsos, a existência de investigação paralela na justiça militar, que atrasa o inquérito civil, e o não aprofundamento sobre a cadeia de comando (não se investiga os superiores hierárquicos dos soldados acusados) (Suárez-Enríquez, 2017). 
Outro ambiente de impunidade se dá na Colômbia, país com alto índice de sentenças condenatórias da Corte IDH. Nesse Estado, tribunais militares eram competentes para julgar violações de direitos humanos cometidas por militares contra civis. No entanto, a Corte IDH já julgou diversos casos em que determina que as cortes militares devem ser competentes para julgamento somente quando os bens violados sejam da alçada castrense. Assim, pode-se afirmar que a jurisdição militar não é a competente para investigar, julgar e sancionar agentes estatais acusados de violações de direitos humanos (Serrano e Salamarca, 2016, p. 41).

Sobre esse país, uma Missão Internacional foi criada para observar os casos de execuções extrajudiciais. Após coletar dados estatísticos, entrevistar membros das forças policiais, Ministério Público, Poder Executivo, advogados e familiares de vítimas, foi produzido e publicado um relatório em $2008^{6}$ que apontou diversos problemas nas investigações dos crimes, tais como: (a) mudanças nas cenas dos locais do delito para dificultar as investigações; (b) grande quantidade de pessoas mortas sem identificação (dados do Ministério da Defesa colombiano apontam que entre 2002 e 2008, 13.068 indivíduos de grupos clandestinos foram mortos em combate, o que ocasiona barreira na investigação dos fatos); (c) ainda que exista um Ministério Público Federal (Fiscalía Geral de la Nación) com competência para investigar violações de direitos humanos, foi identificado que várias denúncias oferecidas a esse órgão por familiares das vítimas eram enviadas para jurisdição penal militar; (d) pressão

6 Vide Informe final de la misión internacional de observación sobre ejecuciones extrajudiciales e impunidad en Colombia, 2008. Disponíve em: <http://www.lawg.org/storage/documents/informe_final_mission ejecuciones_extrajudiciales_oct 08.pdf> Acesso em: 2 ago. 2018. dos membros das forças policiais sobre a Fiscalía para que os inquéritos fossem enviados para os órgãos militares; (e) existência das Fiscalías distantes dos locais onde o crime foi efetuado e algumas são instaladas dentro de guarnições militares.

A Missão Internacional também identificou que entre 2002 e 2007, a Fiscalía realizou 670 inquéritos envolvendo execuções extrajudiciais efetuada por militares e forças policiais, resultando somente em 19 condenações. ${ }^{7}$

A doutrina que aponta sobre os casos de impunidade nos países da América Latina não segue um padrão de análise. Verificam aspectos de cada país e extraem conclusões. Neste sentido, Beristan (2008), quem meIhor analisou as barreiras às sentenças da Corte IDH, indica que os obstáculos para a Justiça pode ser uma conjunção de fatores de caráter estrutural ou normativo, além de falta de interesse, medo ou cumplicidade. A falta de meios ou sobrecarga de pessoal, uma ineficiente investigação prévia, o largo tempo passado do crime, a própria estrutura policial e do Ministério Público (que em alguns casos não assegura independência suficiente), "siguen siendo problemas que condicionan la investigación posterior a la sentencia, acuerdo o informe. En varios de los países analizados, los problemas son parecidos" (Beristan, 2008, p. 440).

Beristain (2008, p. 441-444) então resume os obstáculos mais evidentes para o cumprimento da medida de reparação de se investigar, julgar e sancionar: (a) existência de leis de anistia; (b) legislação interna dos países, com a questão da prescrição dos delitos e ausência da previsão (tipificação) de crimes;

\footnotetext{
7 Vide Informe final de la misión internacional de observación sobre ejecuciones extrajudiciales e impunidad en Colombia, 2008, p. 54. Disponível em: <http://www. lawg.org/storage/documents/informe final mission ejecuciones_extrajudiciales_oct_08.pdf>. Acesso em: 2 ago. 2018.
} 
(c) dificuldades para reabrir processos, como o instituto da coisa julgada, principalmente em casos na jurisdição militar; (d) obstáculos processuais, como o tempo em que permanece aberta uma investigação na fase preliminar ou as mudanças frequentes dos membros do Ministério Público que dificultam a continuidade; (e) existência, em países federais, de tribunais que não reconhecem as obrigações internacionais do país, sendo a saída a federalização do julgamento (em um Tribunal mais geral, de maior hierarquia); (f) desconhecimento, por parte dos que atuam na Justiça, da existência das sentenças da Corte IDH, falta de capacitação e interesse em cumprir as decisões internacionais por parte dos membros do Poder Judiciário; (g) falta de colaboração de instituições do Estado, tanto em proporcionar informações como em fazer diligências; (h) medo e pressão sobre os operadores da justiça onde o nível de segurança é muito precário (como na Colômbia e em Honduras).

Sobre o crime de desaparecimento forçado, constante nas sentenças da Corte IDH, Lessa (2009, p. 1859) elaborou um estudo sobre impunidade e violência sob a ótica da antropologia forense no Brasil, apontando que faz-se necessário um treinamento especializado dos peritos e que a forma como o material humano (ossadas) chega aos institutos médico-legais, descontextualizados, documentados e coletados de forma inadequada, "torna ainda mais difícil o trabalho dos legistas, os quais necessitam associar uma série de evidências e informações específicas aos dados observados durante as análises". Ressalta ainda que outro ponto crítico foi a constatação que nas delegacias de polícia civil "não existe um banco de dados de pessoas desaparecidas onde constem informações de interesse antropológi- co para confrontação com os dados obtidos após a perícia" (LESSA, 2009, p. 1859).

Ao tratar dos crimes de desaparecimento forçado a partir dos casos julgados ela Corte IDH, Matute (2010, p. 268) ressalta que existem quatro causas gerais que podem gerar impunidade: a falta de tipificação do crime, a prescrição, as irregularidades detectadas durante o processo e o transcurso do tempo.

Como não há, na literatura, um estudo empírico específico sobre o tema, após os insights relatados acima, e após a análise dos dados coletados sobre o cumprimento das sentenças selecionadas para serem objeto de estudo, optou-se por investigar as seguintes variáveis: (a) o fator tempo (b); a quantidade de réus e; (c) o tipo de crime envolvido nas sentenças.

A variável sobre o número de réus, embora não tenha sido mencionada na literatura analisada, partiu de um conhecimento prévio e da lógica dos procedimentos criminais, pois quanto maior a quantidade de réus, maior tempo e demanda de trabalho necessários. A partir da leitura dos casos, notouse uma grande variação de acusados nos processos nacionais, que foram desde casos sem nenhum réu identificado e outros com até 48 indiciados.

Em complemento, o andamento dos processos também foi categorizado, de forma a medir em que etapa do procedimento de persecução penal os processos estavam parados. Essa medição foi importante para averiguar em qual instituição nacional havia uma maior predominância de casos.

\section{Metodologia}

A impunidade de agentes estatais nos ca- 
sos julgados pela Corte Interamericana foi objeto de um artigo elaborado Zaverucha e Leite (2016), no qual os autores fizeram um diagnóstico do cumprimento das sentenças da Corte Interamericana e, ao final, identificaram que em nenhuma das sentenças analisadas a medida de reparação para investigar, julgar e sancionar os culpados de violações foi cumprida totalmente nos Estados condenados.

Naquele trabalho, o universo do estudo do cumprimento das sentenças da Corte Interamericana compreendeu as decisões dos casos contenciosos entre janeiro de 2001 e junho de 2013. Para cada sentença considerada, foram analisadas as resoluções de supervisão de cumprimento emitidas pela Corte Interamericana até junho de 2015. ${ }^{8}$ Deve-se ressaltar que todas estas sentenças e resoluções foram consultadas no website da Corte. ${ }^{9}$

Em relação à temporalidade, no estudo dos autores decidiu-se ter como marco inicial o ano de 2001 por ser quando a Corte emitiu sua primeira resolução de supervisão. E o mês de junho de 2013 foi determinado para as sentenças contenciosas porque, ao se observar a atuação da Corte em sua missão de supervisão, notou-se uma média de dois anos para a publicação de sua primeira resolução de supervisão em cada caso. Esta consideração é pertinente porque somente com este documento de supervisão é possível ter dados para verificar quais medidas de reparação foram cumpridas ou não pelos Estados.

Ao final da verificação das decisões, restaram 96 sentenças contenciosas descumpridas e

\footnotetext{
8 Foram excluídos os casos que, apesar de terem sentenças condenatórias até junho de 2013, não possuíam resolução de supervisão até junho de 2015, assim como casos nos quais a resolução de supervisão foi emitida apenas para convocar as partes do processo para uma au diência de supervisão. Dessa forma, ambas as situações foram excluídas por não mostrarem elementos para avaliação do grau de cumprimento das medidas de reparação em cada sentença.

9 http://www.corteidh.or.cr.
}

13 casos totalmente cumpridos e encerrados, o que totalizou 109 casos que preencheram os requisitos da pesquisa e que foram analisados. Em termos percentuais, significa que 88\% das sentenças dentro deste critério não foram totalmente cumpridas, e somente 12\% dos casos foram encerrados.

$\mathrm{Na}$ análise que foi realizada, foram categorizadas as 10 principais medidas de reparação ordenadas pela Corte Interamericana no período escolhido e, para avaliar o cumprimento das medidas, foram utilizados indicadores de cumprimento copiando-se os critérios adotados pela Corte Interamericana nas resoluções de supervisão de suas sentenças. O modelo adotado pelo Tribunal classifica cada medida de reparação em totalmente cumprida (TC), parcialmente cumprida $(P C)$ e pendente de acatamento (PA). Esta última classificação indica que o Estado não realizou qualquer procedimento tendente a cumprir a medida de reparação.

Zaverucha e Leite (2016), então, identificaram que, entre outras questões, em nenhum caso os Estados cumpriram totalmente as condenações para investigar, julgar e sancionar os culpados. Evidenciouse que as reparações mais fáceis são prontamente atendidas pelos Estados, como pagamento de indenizações, ordem para publicar a sentença em jornais de grande circulação, enquanto uma das questões principais, relacionada à punição dos que violam os direitos humanos, principalmente os agentes de Estado, continua sem uma atenção maior dos países.

Assim, foram identificadas 62 sentencas $^{10}$ que não foram totalmente cumpridas, 10 A pesquisa de Zaverucha e Leite (2016) encontrou 67 sentenças envolvendo agentes estatais. No entanto, após uma análise detalhada dos casos, decidiu-se excluir 05 sentenças onde os agentes estatais não eram suspeitos de delitos penais, mas sim de outras espécies (processo administrativo ou civil). Desta forma, o foco da pesquisa é em agentes estatais que cometeram crimes que violam as normas do Sistema Interamericano. 
nas quais a Corte Interamericana determinou que os países investigassem, julgassem e sancionassem os agentes estatais suspeitos de violações de direitos humanos. Ressalte-se que 55 destas medidas de reparação foram consideradas pendentes de acatamento pela Corte IDH, enquanto que 7 foram parcialmente cumpridas.

Desta forma, toda análise que será realizada adiante terá como fundamento os critérios de seleção já expostos e elaborados por Zaverucha e Leite (2016), de forma a dar continuidade ao trabalho já elaborado pelos autores referidos.

Por ser um trabalho ainda exploratório e em fase inicial, não se utilizou nenhum método quantitativo específico. O objetivo da pesquisa é exploratório e descritivo e assim foi realizada uma compilação de dados que foram apresentados em forma de tabelas e gráficos.

De acordo com Reiter (2017, p. 140), a pesquisa exploratória e indutiva não se concentra no comportamento humano, mas diretamente nos mecanismos causais subjacentes que produzem fenômenos sociais. Tal foco em mecanismos causais permite ao pesquisador alcançar um processo de aprendizagem baseado no "por que" e "como" algo aconteceu, sempre reconhecendo que essa explicação flui de uma teoria mantida pelo mesmo investigador.

O estudo também segue um traço descritivo. Explica Guerring (2012) que a pesquisa descritiva descreve algum aspecto do mundo. E, ao fazê-lo, tenta responder perguntas como o quando, quem, de que maneira, um fenômeno ou conjunto de fenômenos ocorrem.

Ao tratar da relação da inferência causal com a inferência descritiva, explica Guerring (2012, p. 740) que a causal é considera- da como uma espécie de racionalidade instrumental, uma vez que se refere à relação empírica entre dois fatores, não envolvendo julgamento explícito sobre o significado normativo da relação resultante. A inferência descritiva, ao contrário, é centrada em um julgamento sobre o que é importante, substantivamente falando, e como descrevê -lo. Ainda de acordo com o autor, descrever alguma coisa é afirmar seu valor final.

Guerring (2012, p. 741) também ressalta que a verdadeira inovação da inferência descritiva é estabelecida delineando um terreno empírico fundamentalmente novo, ou revisando completamente o senso de um terreno estabelecido. Dessa maneira, a descrição acaba se tornando mais difícil do que a análise causal porque impõe um limite mais alto à inovação, exigindo um gasto maior de tempo, energia e recursos. Frequentemente, os benefícios a jusante desse tipo de inovação são maiores que os benefícios correspondentes da análise causal.

Por fim, a pesquisa descritiva muitas vezes é melhor abordada de forma independente, posto que é importante por si mesma, mais do que como um complemento a hipóteses causais. Além disso, a descrição livre da causalidade, em alguns casos (embora nem todos), levará a melhores - mais válidas, precisas e mais completas, descrições da realidade e também ajudará a superar ineficiências no processo de coleta de dados (Guerring, 2012, p. 744).

Neste sentido, os dados coletados nas sentenças buscaram identificar fatores temporais envolvendo os lapsos entre os períodos em que foram cometidos os crimes até a sentença da Corte, e também até 2015. Foram disponibilizadas informações também sobre as resoluções de supervisão, a quan- 
tidade de réus, os tipos de crimes que incidem nos casos e a fase em que o processo de investigação ou julgamento dos agentes estatais culpados estão nos órgãos internos dos países. A escolha destes elementos se deu através de um processo indutivo de observação das resoluções de supervisão de cumprimento de cada sentença, que mostrava a dificuldade dos processos criminais nos países e sumarizava as informações da Comissão Interamericana, dos Estados e dos representantes das vítimas.

\section{Análise dos resultados}

A primeira informação exposta no Quadro 1 refere-se ao número de casos (sentenças) por país. Os dados mostram que entre os processos que estão com status de pendente de acatamento, Peru, Guatemala e Colômbia são os que foram condenados mais vezes, respectivamente.

Quadro 1 - Quantidade de sentenças que possuem condenação em investigar, julgar e sancionar agentes do Estado, por país.

\begin{tabular}{|l|c|c|}
\hline Países & $\begin{array}{l}\text { Processos } \\
\text { Pendentes }\end{array}$ & Parcialmente Cumpridos \\
\hline Argentina & 2 & 1 \\
\hline Bolívia & 2 & 1 \\
\hline Brasil & 1 & 1 \\
\hline Colômbia & 7 & 2 \\
\hline Equador & 2 & 0 \\
\hline El Salvador & 3 & 0 \\
\hline Guatemala & 10 & 1 \\
\hline Honduras & 4 & 0 \\
\hline México & 4 & 0 \\
\hline Panamá & 2 & 0 \\
\hline Paraguai & 2 & 0 \\
\hline Peru & 12 & 1 \\
\hline Uruguai & 1 & 0 \\
\hline Venezuela & 3 & 0 \\
\hline Total & 55 & 7 \\
\hline
\end{tabular}

Fonte: elaboração própria.
No quadro abaixo, encontra-se uma das análises do fator tempo. Autores defendem que uma das causas principais da impunidade dos agentes estatais é o fato de que crimes que ocorreram há muito tempo são difíceis de se investigar e julgar, pela dificuldade em se obterem provas e testemunhas.

Assim, no quadro 2 encontram-se os casos divididos pela época em que ocorreram os crimes. Nota-se que a maioria dos casos tiveram como pano de fundo a década de 90, e em segundo lugar a década de 80. Observou-se também que entre os casos considerados parcialmente cumpridos, $85,7 \%$ ocorreram na década de 90 , demonstrando que este pode ser um indicador de que casos mais recentes podem ter um melhor desenvolvimento nos processos judiciais.

Quadro 2 - Indicação da década em que ocorreram os crimes.

\begin{tabular}{|c|c|c|c|c|}
\hline & Processos & $\begin{array}{l}\text { Penden- } \\
\text { tes }\end{array}$ & $\begin{array}{l}\text { Par- } \\
\text { cial- } \\
\text { mente }\end{array}$ & $\begin{array}{l}\text { Cumpri- } \\
\text { dos }\end{array}$ \\
\hline Década do Fato & Quantitativo & Percentual & $\begin{array}{l}\text { Quan- } \\
\text { titativo }\end{array}$ & $\begin{array}{l}\text { Percen- } \\
\text { tual }\end{array}$ \\
\hline Década de 70 & 7 & $12,7 \%$ & 0 & $0,0 \%$ \\
\hline Década de 80 & 14 & $25,5 \%$ & 1 & $14,3 \%$ \\
\hline Década de 90 & 31 & $56,4 \%$ & 6 & $85,7 \%$ \\
\hline Década de 2000 & 3 & $5,5 \%$ & 0 & $0,0 \%$ \\
\hline Total & 55 & $100,0 \%$ & 7 & $100,0 \%$ \\
\hline
\end{tabular}

Fonte: Elaboração própria.

Ainda com relação ao fator tempo, o Quadro 3 traz algumas médias temporais de relevo. A primeira delas informa o tempo médio entre o ano do crime que originou o caso e a sentença prolatada pela Corte Interamericana. Observe-se que os processos levam em média 16,5 anos, nas sentenças que estão pendentes de acatamento, e 13,9 anos 
nos processos parcialmente cumpridos. E este é um lapso temporal bastante elevado.

A outra média refere-se à data do fato e 2015. Esta média foi elaborada para se ter uma noção do tempo médio que os processos levam desde o fato que o originou até 2015, pois até este ano os agentes estatais culpados de violações de direitos humanos não foram totalmente julgados em seus países. O cálculo revelou que estes processos ocorreram em média há 25 anos atrás.

Quadro 3 - Médias gerais temporais (medidas em anos) e a média da quantidade de resoluções de supervisões emitidas pela Corte Interamericana até 2015, para cada caso.

\begin{tabular}{|l|c|c|}
\multicolumn{1}{|l|}{ Médias Gerais } & $\begin{array}{l}\text { Processos } \\
\text { Pendentes }\end{array}$ & $\begin{array}{l}\text { Parcialmen- } \\
\text { te Cumpri- } \\
\text { dos }\end{array}$ \\
\hline Tempo entre o fato e a sentença & 16,5 & 13,9 \\
\hline Tempo entre a sentença e 2015 & 9,7 & 10,1 \\
\hline Tempo entre o fato e 2015 & 25,7 & 24 \\
\hline $\begin{array}{l}\text { Resoluções de Supervisão (até } \\
\text { 2015) }\end{array}$ & 3,4 & 2,7 \\
\hline
\end{tabular}

Fonte: Elaboração própria.

Por sua vez, foi importante estabelecer qual a média de tempo entre a emissão da sentença da Corte Interamericana e o ano de 2015. O objetivo é fazer uma relação com a quantidade de resoluções de supervisão que a Corte Interamericana tem emitido nos processos.

Estas resoluções de supervisão são um trabalho que a Corte elabora com o objetivo de supervisionar o cumprimento das medidas de reparação estabelecidas na sentença, e para tanto, depois de convocar as partes do processo, receber relatórios, realizar audiências, o Tribunal emite uma resolução, informando se cada medida de reparação foi totalmente cumprida, cumprida parcialmente ou está pendente de acatamento. Assim, estabelecer a média da quantidade destas resoluções dará uma noção se a Corte tem pressionado ou não os países a cumprirem suas sentenças.

Neste sentido, observou-se ainda no Quadro 3 um tempo médio de 10 anos entre as sentenças e o ano de 2015. E por sua vez, uma média de 3,4 resoluções de supervisão nos processos que ainda estão pendentes, e 2,7 nos casos parcialmente cumpridos. Assim, pode-se afirmar que a proximadamente a cada 3 anos, a Corte emite uma resolução de supervisão nos processos. No entanto, os dados mostram uma menor quantidade de resoluções de supervisão nos casos parcialmente cumpridos (2,7), o que pode vir a denotar que a influência da Corte em seu trabalho de supervisão não seja um fator vital, isoladamente, para o cumprimento dos processos.

Outro fator que pode ter incidência na impunidade dos agentes estatais é o número de réus ou suspeitos envolvidos nos crimes cometidos, expostos no Quadro 4. Note-se que nos casos pendentes de acatamento, um percentual de $40 \%$ representa os processos nos quais os órgãos estatais não investigaram ou não encontraram os suspeitos, assim não podendo individualizá-los. Este é o grau mais baixo do cumprimento da medida de reparação, pois significa que ou os órgãos investigativos por algum motivo não estão investigando, ou devido ao tempo decorrido desde o crime, há dificuldades para se encontrarem novas provas. Em segundo lugar estão os casos entre 1 e 5 réus, o que se comparando com os casos parcialmente cumpridos, deveria facilitar o cumprimento, mas não é o que ocorre na prática. 
Quadro 4 - Quantidade de réus em cada processo.

\begin{tabular}{|c|c|c|c|c|}
\hline & Processos & Pendentes & Parcialmente & Cumpridos \\
\hline Quantidade de réus & Quantitativo & Percentual & Quantitativo & Percentual \\
\hline entre 1 e 5 & 18 & $32,7 \%$ & 3 & $42,9 \%$ \\
\hline entre 6 e 10 & 5 & $9,1 \%$ & 4 & $57,1 \%$ \\
\hline entre 11 e 20 & 5 & $9,1 \%$ & 0 & $0,0 \%$ \\
\hline Mais de 21 & 5 & $9,1 \%$ & 0 & $0,0 \%$ \\
\hline Sem réus individualizados & 22 & $40,0 \%$ & 0 & $0,0 \%$ \\
\hline Total & 55 & $100,0 \%$ & 7 & $100,0 \%$ \\
\hline
\end{tabular}

Fonte: Elaboração própria.

Um outro elemento de impacto que pode ser encontrado na investigação de um crime é o tipo do delito cometido (Gráfico 1). Existem crimes que deixam evidências de forma mais clara, enquanto outros trazem dificuldades para a obtenção de provas, como é o caso do desaparecimento forçado, onde não são encontrados os restos mortais das vítimas para a realização de perícias. E não é sem razão que este crime está em segundo lugar no número de incidência nos processos pendentes de acatamento. $\mathrm{Na}$ análise dos tipos de crimes envolvidos, outros delitos se destacam: em primeiro lugar assassinato, seguido de tortura e detenção ilegal/arbitrária.

Gráfico 1 - Incidência dos crimes (em quantidade).

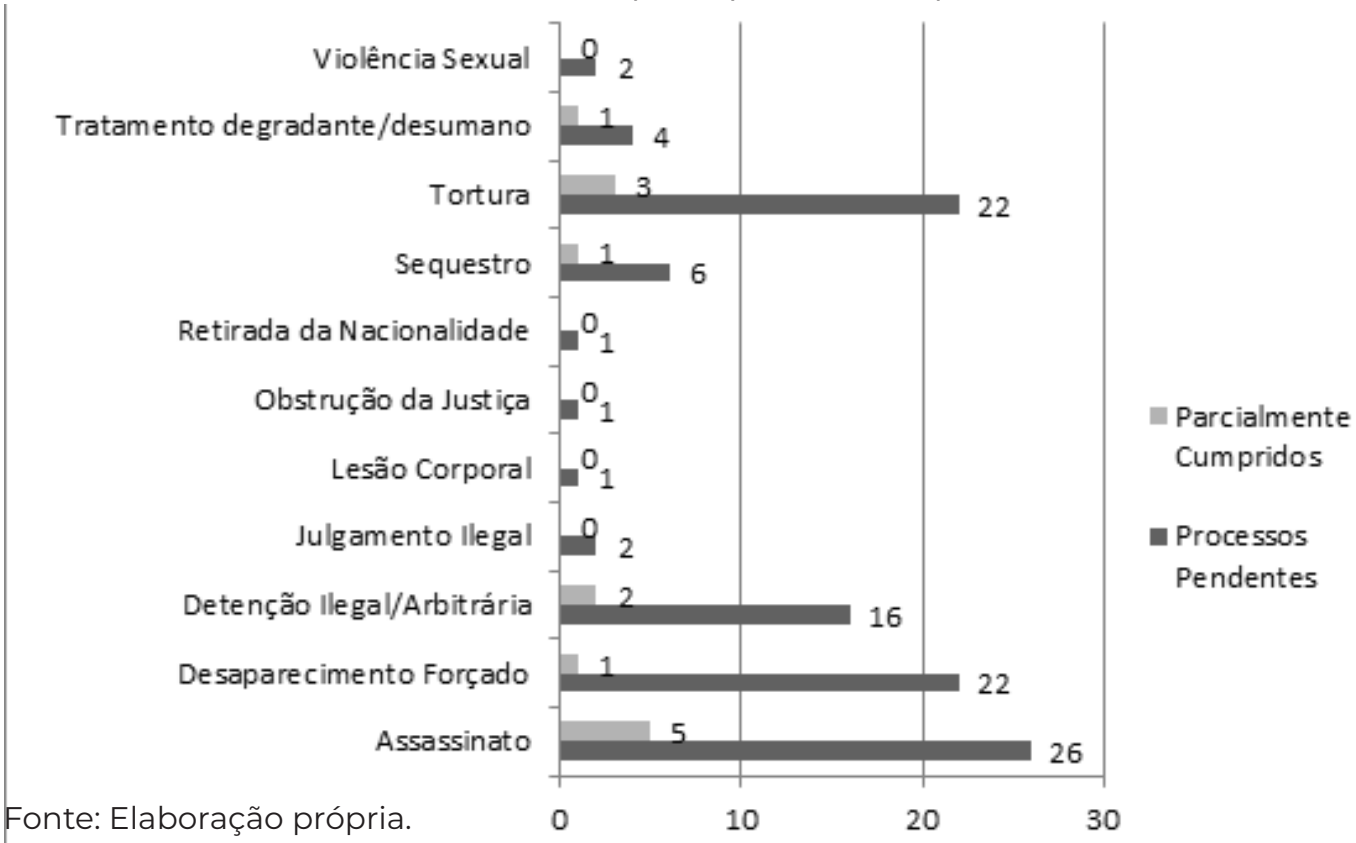

O Gráfico 1 também aponta que nos 7 casos que foram parcialmente cumpridos, o desaparecimento forçado ocorreu apenas uma vez, fazendo transparecer que este crime seja um fator de impacto na impunidade e que tenha correlação com a não investigação e julgamento dos agentes estatais, já que nos casos pendente de acatamento ele está em segundo lugar na ordem de incidência. Ou seja, quando não há o crime de desaparecimento forçado, é maior a probabilidade dos Estados investigarem e julgarem os culpados (ainda que parcialmente). 
É importante ressaltar que nestes processos julgados pela Corte Interamericana, para cada caso podem ocorrer diversos crimes originados de um único fato, como a detenção ilegal, tortura e assassinato em conjunto. Assim, é fundamental também estabelecer futuramente, com maiores detalhes, se estes crimes conjuntos influenciam o cumprimento da sentença da Corte.

Questão fundamental, depois de todos estes fatores, foi identificar em que fase os processos se encontravam atualmente nos órgãos internos dos países. Assim, buscou-se diagnosticar onde se encontra o entrave para a investigação, julgamento e sanção dos agentes estatais suspeitos de violações de direitos humanos, dentro do sistema de persecução penal do ordenamento jurídicos dos Estados.

Neste sentido, tendo em vista a diversidade de situações existentes, onde muitos casos possuíam mais de 1 ou 2 réus, e continham processos distintos, em fases diferentes, estabeleceu-se uma categorização das fases processuais a partir da situação dos processos criminais nacionais informados nas resoluções de supervisão de cumprimento da Corte Interamericana. Desta forma, cada número representa uma fase do processo de investigação, julgamento e sanção dos culpados dentro dos países. Estes dados estão no Quadro 5. Frise-se que os processos criminais nos Estados da América Latina seguem quase um mesmo padrão: inicia-se com uma investigação preliminar por parte da Polícia ou do Ministério Público, sendo que este oferece uma denúncia criminal perante o Poder Judiciário, que por sua vez profere uma decisão judicial, seja ela em primeira, segunda ou terceira instância. Não foi verificado o caso de uma quarta instância nos processos.

Quadro 5 - Quadro de descrição das fases do processo.

\begin{tabular}{|c|c|}
\hline $\begin{array}{l}\text { Código da Fase em Que o } \\
\text { Processo se Encontra }\end{array}$ & Descrição \\
\hline 0 & Sem réus individualizados, ou o Ministério Público ou Polícia está em investigação preliminar \\
\hline 1 & Processo Judicial iniciado, mas faltam outros suspeitos serem identificados e investigados \\
\hline 2 & Processo Judicial está em primeira instância. \\
\hline 3 & O Processo teve decisão de primeira instância. \\
\hline 4 & O Processo está em segunda instância judicial ou já recebeu decisão de segunda instância. \\
\hline 5 & Processo em terceira instância. \\
\hline 6 & Processo teve decisão de terceira instância ou transitada em julgado. \\
\hline 7 & $\begin{array}{l}\text { Réus condenados em 1a., 2a. ou 3a. instância, e outros em investigação preliminar pela polícia ou Minis- } \\
\text { tério Público. }\end{array}$ \\
\hline 8 & Réus condenados e outros respondendo a processos judiciais. \\
\hline 9 & Réus condenados, mas algum está foragido, não cumprindo assim a penalidade devida. \\
\hline 10 & $\begin{array}{l}\text { Processos na Justiça discutindo questões processuais/preliminares. Ex.: prescrição, coisa julgada, lei de } \\
\text { anistia, nulidade, etc. }\end{array}$ \\
\hline
\end{tabular}

Fonte: Elaboração própria. 
Em complemento, o Quadro 6 apresenta os dados principais. Estabelece em que fase os processos dentro dos países pararam, no sentido de se investigar e julgar os agentes estatais. Observe-se que estas informações se referem à dados coletados nas últimas resoluções de supervisão emitidas pela Corte Interamericana em cada processo. No entanto, não reflete o status do processo dentro dos países em 2015, pois há situações de sentenças que foram proferidas pela Corte Interamericana há dez anos, e que tiveram a última resolução de supervisão emitida em 2010, 2012, por exemplo. Assim, desde a última resolução até 2015, pode ser que os processos tenham tido alguma outra movimentação real, mas que ainda não foi exposta ou reconhecida pela Corte Interamericana, que o faz somente através destas resoluções.

Quadro 6 - Fase de investigação ou processual em que os processos para se investigar e julgar os agentes estatais pararam dentro dos países.

\begin{tabular}{|c|c|c|c|c|}
\hline \multicolumn{2}{|c|}{$\begin{array}{c}\text { Proces- } \\
\text { sos }\end{array}$} & Pendentes & \multicolumn{1}{c|}{$\begin{array}{c}\text { Parcial- } \\
\text { mente }\end{array}$} & Cumpridos \\
\hline $\begin{array}{c}\text { Tipo da } \\
\text { Fase de } \\
\text { Investiga- } \\
\text { cão/Pro- } \\
\text { cessual }\end{array}$ & Quant. & Percentual & Quant. & Percentual \\
\hline 0 & 28 & $51 \%$ & 0 & $0 \%$ \\
\hline 1 & 2 & $4 \%$ & 0 & $0 \%$ \\
\hline 2 & 8 & $15 \%$ & 2 & $29 \%$ \\
\hline 3 & 0 & $0 \%$ & 0 & $0 \%$ \\
\hline 4 & 1 & $2 \%$ & 1 & $14 \%$ \\
\hline 5 & 1 & $2 \%$ & 0 & $0 \%$ \\
\hline 6 & 0 & $0 \%$ & 0 & $0 \%$ \\
\hline 7 & 7 & $13 \%$ & 0 & $0 \%$ \\
\hline 8 & 4 & $7 \%$ & 1 & $14 \%$ \\
\hline 9 & 0 & $0 \%$ & 3 & $43 \%$ \\
\hline 10 & 4 & $7 \%$ & 0 & $0 \%$ \\
\hline Total & 55 & $100 \%$ & 7 & $100 \%$ \\
\hline
\end{tabular}

Fonte: Elaboração própria.
Os dados do Quadro 6 mostram que nos processos que estão pendentes de acatamento, 51 \% dos casos estão sem réus identificados ou ainda em etapa preliminar de investigação pelo Ministério Público. Este é um péssimo indicador porque mostra que os processos não saíram da etapa inicial. Em segundo lugar estão os processos em primeira instância (15\%), e em terceiro estão os processos nos quais já houve condenação, mas há ainda outros réus sendo investigados pelo Ministério Público ou polícia.

Por sua vez, nos 07 processos que foram parcialmente cumpridos, em destaque estão 3 deles nos quais os réus foram condenados, mas há algum ainda foragido, e 2 casos que estão em primeira instância judicial.

Percebe-se, por outro lado, que a escala de avaliação adotada pela Corte Interamericana para avaliar o cumprimento das medidas de reparação nas sentenças não parece estabelecer um padrão único. Veja-se que processos que foram considerados pendentes de acatamento estão nas mais diversas fases processuais, enquanto que há dois processos nos quais a Corte considerou parcialmente cumprido, mas que estão em primeira instância judicial.

Neste sentido, para o aprofundamento desta pesquisa e trabalhos futuros, sugere-se abandonar esta escala de pendente de acatamento e parcialmente cumprido. A sugestão é avaliar se a medida de reparação foi parcialmente cumprida ou totalmente cumprida. E se foi parcialmente cumprida, criar uma escala de avaliação própria, de forma a medir de forma mais exata o seu cumprimento. 


\section{Considerações finais}

Os dados analisados apresentam alguns fatores que podem contribuir para que os agentes estatais suspeitos de violações de direitos humanos não sejam julgados em seus Estados, após uma condenação do país pela Corte Interamericana. Entre eles, anteriormente reconhecido pela Corte Interamericana e pela doutrina, está o fator tempo. Como verificado, os processos levam em média 15 anos após o fato que o gerou, para ter uma sentença da Corte Interamericana, favorecendo uma perda de provas e testemunhas fundamentais. O cálculo médio revelou que os crimes ocorreram há mais de 25 anos, e muitos dos processos criminais deles ainda nem concluíram a fase de investigação preliminar pela Polícia ou Ministério Público.

Dos casos que foram considerados pendentes de acatamento, 51\% não tinham réus individualizados ou as investigações dos crimes não foram concluídas, o que é um fato bastante alarmante, e 15\% estavam na primeira instância judicial, fase inicial do processo.

Por outro lado, entre os processos que foram considerados parcialmente cumpridos pela Corte Interamericana, três fatores se destacam: $85,7 \%$ deles tiveram origem em fatos na década de 90. Apenas um caso ocorreu na década de 80 e não teve nenhum crime da década 70. Veja-se que entre os casos considerados pendentes de acatamento, $12,7 \%$ tiveram lugar na década de 70, e 25,5\% na década de 80. Assim, percebe-se, a partir destes dados, que quanto mais recente o crime (a partir da década de 90), há uma maior probabilidade de se investigar e julgar os culpados (ainda que parcialmente, como identificado).

Outro fator de relevo foi o número de réus: em todos os casos considerados parcialmen- te cumpridos, todos tinham entre 01 e 10 réus, o que facilita a investigação e julgamento (quanto menor o número de réus, melhor). No caso dos processos pendentes de acatamento, existiam 5 casos entre 11 e 20 réus, e 05 casos com mais de 21 réus, o que de fato dificulta ainda mais qualquer investigação. Ademais, outro fator relevante neste tipo de fator é que 22 casos não tinham réus individualizados, ou seja, a investigação não chegou sequer a apontar suspeitos de autoria.

Um terceiro fator de relevo foi o tipo de crime envolvido nos casos. Nos processos parcialmente cumpridos, em somente um caso ocorreu o crime de desaparecimento forçado. Note-se que este crime teve uma alta incidência nos casos pendentes de acatamento (ocorreu 22 vezes em 55 casos), o que faz com que a existência deste delito seja um fator que contribua para a impunidade, haja vista a dificuldade de investigação ante a inexistência dos corpos para a realização de perícias.

Por outro lado, 51\% dos casos pendentes de acatamento estavam na fase preliminar de investigação, seja com o Ministério Público ou a Polícia. Isto revela que um grande entrave para o andamento da persecução criminal encontra-se justamente nesta fase inicial de investigação. No entanto, a pesquisa ainda não foi capaz de revelar se este alto índice se concretiza ante a burocracia dos órgãos públicos, a falta de estrutura ou mesmo a falta de vontade de se investigar os casos. Apenas uma pesquisa qualitativa mais profunda poderia indicar alguma causa.

Critica-se também a utilização da escala de avaliação realizada pela Corte Interamericana, quando considera que as medidas de reparação foram pendentes de acatamento, parcialmente cumpridas ou totalmen- 
te cumpridas. A partir da análise de dados, observou-se que casos que foram considerados parcialmente cumpridos estavam ainda na fase de primeira instância judicial, enquanto que processos que estavam pendentes de acatamento estavam em fases mais avançadas. Assim, a avaliação da Corte se mostra puramente subjetiva, sem conceitos claros. A sugestão para pesquisas sobre o cumprimento das medidas de reparação da Corte Interamericana é abandonar esta classificação e considerar os casos como totalmente cumpridos e parcialmente cumpridos, e nestes últimos, elaborar uma escala de avaliação específica, mais fidedigna aos estágios de evolução do cumprimento das sentenças, se necessário.

Por fim, cumpre ressaltar que esta não é uma pesquisa exaustiva, e que aborda apenas elementos chaves para a questão da impunidade dos agentes estatais proveniente de casos julgados pela Corte Interamericana, a partir do andamento dos processos criminais nos Estados. Seguramente outros fatores contextuais podem ter relevância para o descumprimento das ordens da Corte Interamericana, como o contexto político no momento da violação (se havia um estado democrático ou não), o nível de burocracia, a independência do poder judiciário, do ministério público e das polícias, entre outros. No entanto, os resultados encontrados, apesar de apresentarem resultados dentro de um senso comum da prática judiciária da América Latina, mostram-se relevantes por serem pioneiros em mostrar, através de dados empíricos, a problemática envolvendo a medida de reparação da Corte Interamericana que é a mais dificultosa para se cumprir, mas que é uma das mais importantes dentro de um panorama latino-americano que possui um histórico de graves violações de direitos humanos.

Ressalte-se que estes são elementos que são diretamente relacionados com a impunidade dos agentes estatais no âmbito nacional. No entanto, há outro elemento que poderia ter influência nos estados para persuadir os atores nacionais ao cumprimento das medidas de reparação, que é o processo de supervisão de cumprimento de sentenças da Corte Interamericana. Sobre o tema, Leite (2017) aponta que este mecanismo de fiscalização, que é realizado quase que exclusivamente pela Corte IDH, esconde uma total omissão dos órgãos políticos da OEA, que não mostram interesse em discutir as sentenças que não são cumpridas, e assim não utilizam do meio diplomático da organização para pressionar ou auxiliar os países.

Por sua vez, a doutrina (Garcés, 2008; Çali; Koch, 2014) tem afirmado que o mecanismo de supervisão de sentenças criado pelo Conselho da Europa, que determinou um órgão político específico com o objetivo de supervisionar o cumprimento de cada uma das sentenças do Tribunal Europeu dos Direitos Humanos (TEDH) - o Comitê de Ministros - tem funcionado de forma eficiente. Estas afirmações são corroboradas com as estatísticas dos Relatórios Anuais do TEDH"1", que mostram que após uma modificação do mecanismo de supervisão, onde criou-se procedimentos específicos para casos mais simples e complexos, adotando-se uma postura mais de diálogo e menos sancionatória, tem persuadido os estados e aumentado o número de sentenças que são totalmente cumpridas. Este fator internacional não é a causa do descumprimento das sentenças pelos países, mas poderia ter influência nos processos. Assim, como pauta complemen-

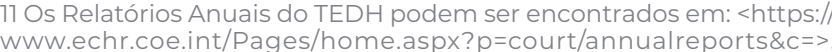
Acesso em: 20 nov 2018. 
tar aos fatores nacionais da impunidade, sugere-se uma pesquisa comparada (Corte IDH e TEDH) para averiguar os êxitos e deficiências de ambos os sistemas no tocante à supervisão das sentenças dos respectivos tribunais de direitos humanos.

\section{Referências}

Alter, K. J. The New Terrain of International Law: Courts, Politics, Rights. Oxfordshire: Princeton University Press. Edição do Kindle.

Álvarez, J. C. (2012). El Concepto De Impunidad A La Luz Del Derecho Internacional: Una Aproximación Sistémica Desde El Derecho Internacional Penal Y El Derecho Internacional De Los Derechos Humanos. REEI, n. 24, pp. 1-31.

Ambos, Kai. (1999). Impunidad y Derecho Penal Internacional. $2^{a}$. ed. Buenos Aires: Ad Hoc.

Anagnostou, D.; Mungiu-Pippidi, A. (2014). Domestic Implementation of Human Rights Judgments in Europe: Legal Infrastructure and Government Effectiveness Matter. The European Journal of International Law, vol. 25, n. 1, 2014, pp. 205-227.

Basch, F.; Filippini, L.; Laya, A.; Nino, M., et al. (2010). The Effectiveness of the Inter-American System of $\mathrm{Hu}$ man Rights Protection: A Quantitative Approach to its Functioning and Compliance with its Decisions. SUR - International Journal on Human Rights, vol. 7, n. 12, 2010, pp. 9-36.

Beristain, C. M. (2009). Diálogos sobre la Reparación. Qué Reparar en Los Casos de Violaciones de Derechos Humanos. San José: Instituto Interamericano de Derechos Humanos.

(2008). Diálogo Sobre la Reparación: Experiencias en el Sistema Interamericano de Derechos Humanos. Tomo I. San José: Instituto Interamericano de Derechos Humanos.

Briceño-Donn, M. (2001). El papel de los actores de Sistema Interamericano en el Proceso de Fortalecimiento. Revista IIDH, n. 30-31, pp. 237-243.

Çali, B.; Koch, A. (2014). Foxes Guarding the Foxes? The Peer Review of Human Rights Judgments by the Committee of Ministers of the Council of Europe. Human Righs Law Review, vol. 14, pp. 301-325.

Carulla, S. R. (2007). El sistema europeo de protección de los derechos humanos y el Derecho español. Bar- celona: Atelier.

Carvalho Filho, L, F. (2004). Impunidade no Brasil - CoIônia e Império. Estudos Avançados, vol. 18, n. 51, 2004, pp. 181-194.

Cavallaro, J. L.; Brewer, S. (2008). Reevaluating Regional Human Rights Litigation in the Twenty-First Century: The Case of the Inter-American Court. The American Journal of International Law, vol. 102, pp. 768-827. Dothan, S. (2011). Judicial Tactics in the European Court of Human Rights. Chicago Journal of International Law, vol. 12, n. 1, pp. 115-142.

Garcés, A. V. (2008). Sistemas Europeo y Americano de Protección de Derechos Humanos. Coincidencias, Fraccionamientos Temporales y Mutuas Influencias. In: Sánchez, Miguel Revenga; Garcés, A. V. (eds.): Tendencias Jurisprudenciales de La Corte Interamericana y el Tribunal Europeo de Derechos Humanos. Valencia: Tirant lo Blanch, pp. 17-70.

García, F. S. (2007). Derechos Humanos. Efectos de las sentencias internacionales. México: Porrúa.

González-Salzberg, D. A. (2010). The Effectiveness Of The Inter-American Human Rights System: A Study Of The American States' Compliance With The Judgments Of The Inter-American Court Of Human Rights. International Law: Revista Colombiana de Derecho Internanacional, n. 15, pp. 115-142.

Grewal, S.; Voeten, E. (2012). The Politics of Implementing European Court of Human Rights Judgements. Acesso em: 10 set. 2017. Paper disponível no portal SSRN: <https://ssrn.com/abstract=1988258>.

Guerring, J. (2012). Mere description. British Journal of Political Science, vol. 42, n. 4, 2012, pp. 721-746.

Hawkins, D.; Jacoby, W. (2010). Partial compliance: a comparison of the European and inter-American courts of human rights. Journal of International Law and International Relations, vol. 6, n. 1, pp. 35-85.

Hillebrecht, C. (2014). Domestic Politics and International Human Rights Tribunals. The Problem of Compliance. New York: Cambridge University Press.

Huneeus, A. (2011). Courts Resisting Courts: Lessons from the Inter-American Court's Struggle to Enforce Human Rights. Cornell International Law Journal, n. 493, pp. 493-533.

Krsticevic, V. (2007). Reflexiones sobre la ejecución de sentencias de las decisiones del sistema interamericano de protección de derechos humanos. In: Krsticevic, V.; Tojo, L. (coord.) Implementación de las decisiones del Sistema Interamericano de Derechos Humanos: Jurisprudencia, normativa y experiencias nacionales. 
Buenos Aires: Center for Justice and International Law - CEJIL, p. 15-112.

Le Clercq, J. A.; Cháidez, A.; Rodríguez, G. (2016). Midiendo la impunidad en América Latina: retos conceptuales y metodológicos. Iconos. Revista de Ciencias Sociales, n. 55, pp. 69-91.

Leite, R. (2017). Análise Dos Processos E Atores Políticos Na Supervisão De Sentenças Da Corte Interamericana De Direitos Humanos. In: Simone P. V.; Michele G. M.; Sandra A. S.; Lucas R. M.; Lorena G. H.; Helga, N A. (Org.). América Latina em foco: Novas perspectivas de análise sobre a região. 1ed. Porto Alegre: Terra da Ideia, pp. 99-119.

Lessa, A. (2009). Violência e impunidade em pauta: problemas e perspectivas sob a ótica da antropologia forense no Brasil. Ciência e Saúde Coletiva, vol.14, n.5 pp. 1855-1863.

Matute, J. D. (2010). El Concepto De Impunidad: Leyes De Amnistía Y Otras Formas Estudiadas Por La Corte Interamericana De Derechos Humanos. In: Fundación Konrad-Adenauer (org.). In: Sistema interamericano de protección de los derechos humanos y derecho penal internacional. Montevideo: Fundación Konrad -Adenauer, pp. 263-294.

Orentlicher, Diane. (2004). Informe de la Sra. Diane Orentlicher, experta independiente encargada de actualizar el conjunto de principios para la lucha contra la impunidad - Conjunto de principios actualizado para la protección y la promoción de los derechos humanos mediante la lucha contra la impunidad. Comissão de Direitos Humanos da ONU. Doc. E/CN.4/2005/102/ Add.1. Disponível em: <http://ap.ohchr.org/documents/ dpage_s.aspx?si=E/cn.4/2005/102/Add.1>. Acesso em 02 ago 2018.

Pasqualucci, J. M. (2003). The Pratice and Procedure of The Inter-American Court of Human Rights. Cambridge: Cambridge University Press.

Poertner, M. (2013). Institutional Capacity for Compliance: Domestic Compliance with the Inter-American Court of Human Rights. Paper presented at the Annual Meeting of the American Political Science Association, Chicago, IL, August 29 - September 1, pp. 1-33.

Reiter, B. (2017). Theory and Methodology of Exploratory Social Science Research. Government and International Affairs Faculty Publications, University of South Florida, pp. 129-150. Disponível em: < http:// scholarcommons.usf.edu/gia_facpub/132>. Acesso em: 02 ago 2018
Schneider, J. (2012). Implementation of Judgments: Should Supervision Be Unlinked From The General Assembly Of The Organization Of American States? Revista Interamericana y Europea de Derechos Humanos - Inter-American and European Human Rights Journal ,v. 5, n.1, pp. 197-215.

Serrano, A. G.; Salamanca, M. I. M. (2016). La jurisdicción militar desde los fallos de la corte interamericana en relación con Colombia. Saber, Ciencia y Libertad, vol. 11, n.1, pp. 37-60.

Silva, A. R.; Echeverria, A. Q. D. (2015). Tentativas de contenção do ativismo judicial da Corte Interamericana de Direitos Humanos. Revista de Direito Internacional - Uniceub, v. 5, número especial, pp. 392-409. Suárez-Enríquez, X. (2017). Overlooking Justice. Human Rights Violations Committed by Mexican Soldiers against Civilians are Met with Impunity. Disponível em: <https://www.wola.org/wp-content/ uploads/2017/11/WOLA_MILITARY-CRIMES_REP_ENGLISH.pdf>. Acesso em: 15 out 2018.

Voeten, E (2014). Domestic Implementation of European Court of Human Rights Judgments: Legal Infrastructure and Government Effectiveness Matter: A Reply to Dia Anagnostou and Alina Mungiu-Pippidi. The European Journal of International Law, vol. 25 n. 1, pp. 229-238.

Zaverucha, J.; Leite, R. (2016). A impunidade de agentes estatais nos casos julgados pela Corte Interamericana. Revista Brasileira de Segurança Pública, vol. 10, n. 1, pp. 88-107.

\section{Data de submissão: 25/10/2017}

Data de aceite: $26 / 04 / 2019$ 